\title{
EDITORIAL
}

(O) $10^{\mathrm{TH}}$ ANNIVERSARY

\section{Happy birthday, Nature Reviews Urology!}

B irthdays are funny things. Whilst they are an occasion for celebration, they also represent the passing of time-often far more quickly than we expect -and offer us an opportunity to look back and consider how things have changed. It is hard to believe that Nature Reviews Urology has celebrated ten of them, and we now present to you our special $10^{\text {th }}$ Anniversary issue.

The past decade has been one of enormous change in clinical medicine. Paradigm shifts in understanding the pathogenesis, diagnosis and treatment of diseases have meant that many of our patients face far brighter futures than were possible in 2004. Urology is no exception, and, in fact, urologists often lead the way in pioneering new technology and embracing new ideas. The rise of robotic surgery and the enthusiasm with which urologists engage with social media are but two small examples.

Likewise, we hope that the same can be said for Nature Reviews Urology as a journal. When we launched in 2004 as Nature Clinical Practice Urology, our then Editor-inChief, Peter Scardino, described our mission statement as to produce articles that were "reliable, relevant to your practice, informative, balanced and objective". This ethos continues to underscore everything that we do, but, at the same time, we are proud of how the journal has evolved over the last decade to keep up with a changing field and a changing world. In 2014, NRU can be read in print, online, on your mobile phone and on an iPad app. We are visible on Facebook through the Nature Reviews

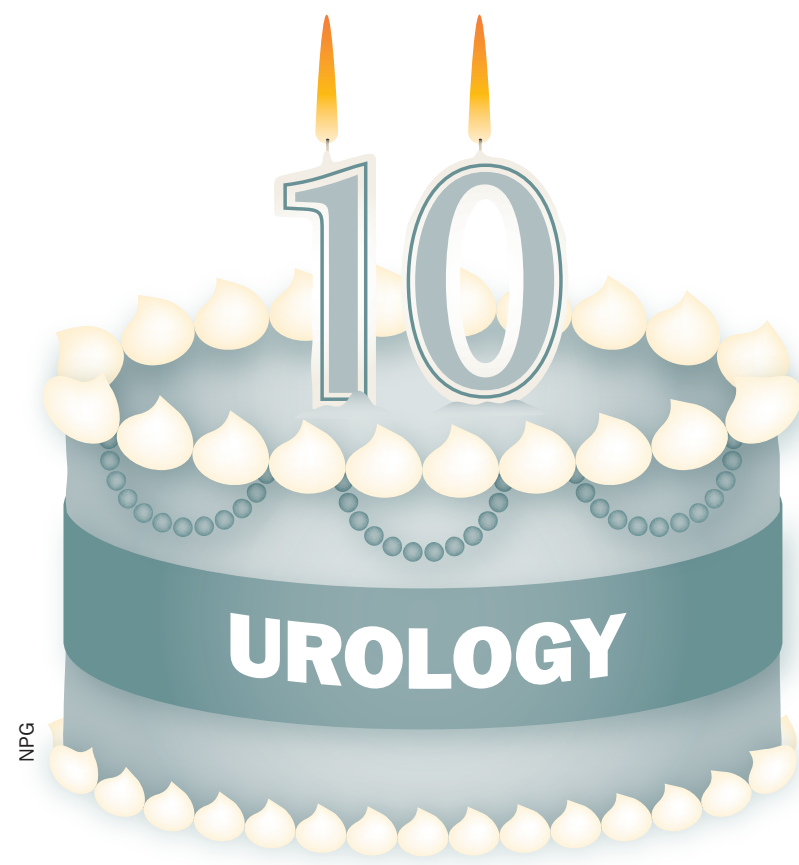

page, and we have a dedicated Twitter account, via which editors and readers can directly engage. We continue to source the most up-to-date and interesting Reviews from the most well-respected names in the field, whilst also providing opportunities for up-and-coming authors-the key opinion leaders of the future. Our rebrand to the Nature Reviews format in 2009 enabled us to improve our print and online layouts, making them even more accessible to our readers. Our in-house Art Team produces some of the most attractive and easily accessible figures available.

In this Anniversary issue, we have put together a series of special articles to mark the occasion. An infographic provides an overview of the journal in numbers. We also present a set of specially commissioned Decade In Review articles, which capture the wealth of information we have learned in urology over the past decade. In these articles, based on our News \& Views format, we asked six of our esteemed advisory board members to discuss the most important changes in their field over the past 10 years, in less than 1,600 words and with only 10 references. It soon became abundantly clear that these limits would make it difficult to cover the many varied changes that we have seen across urology! As part of this one-off series of articles, W. Marston Linehan and Chris Ricketts discuss the changes that have occurred during the past 10 years in renal cancer, Emmanuel Weyne and Maarten Albersen consider progress in sexual medicine, Behfar Ehdaie and Peter Scardino discuss the decade in prostate cancer, Dan Theodorescu and James Costello outline the biggest issues in bladder cancer, Howard Goldman and Marisa Clifton offer their thoughts on 10 years in female urology, and Baris Turkbey and Peter Choyke consider advances in urological imaging. We have also put together a special anniversary Viewpoint, in which members of our board offer their personal views on how things have changed over 10 years in urology, and their opinions on what the next decade will bring

Like the title of our Anniversary Viewpoint, this editorial serves as a means to look forward and look back. As we look back, we can consider how far we've come; as we look forward, we make a new promise: to continue to provide you with the best quality urological Reviews and to keep you up-to-date with the latest news in our varied and evolving field. I would like to extend my thanks to everyone who has contributed to the success of $N R U$ over the years, as advisors, authors, reviewers and readers. We hope that you will all join our celebrations, and enjoy our special Anniversary with us.

doi:10.1038/nrurol.2014.275

\section{$4 .$. urologists often lead the way in pioneering} new technology and embracing new ideas 77
Annette Fenner is the Chief Editor of Nature Reviews Urology.

The author declares no competing interests. 